\title{
Association of BRAF gene and TSHR with cervical lymph node metastasis of papillary thyroid microcarcinoma
}

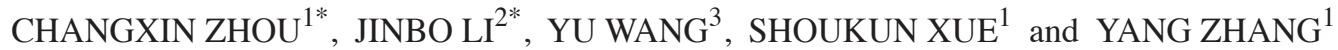 \\ ${ }^{1}$ Department of Thyroid and Breast Surgery, Liaocheng People's Hospital, Liaocheng, Shandong 252000; \\ ${ }^{2}$ Department of General Surgery, Gaotang County People's Hospital; ${ }^{3}$ Department of Thoracic Surgery, \\ Liaocheng Tumor Hospital, Liaocheng, Shandong 252800, P.R. China
}

Received January 3, 2018; Accepted September 13, 2018

DOI: $10.3892 / \mathrm{ol} .2018 .9572$

\begin{abstract}
Differences in BRAF gene mutation frequency and thyroid-stimulating hormone receptor (TSHR) protein expression in thyroid tissues were detected to investigate their association with local tissue invasion and cervical lymph node metastasis potential of papillary thyroid microcarcinoma (PTMC). The BRAF gene mutation frequency and TSHR expression in PTMC patients were detected via qPCR and immunohistochemical method, and the association between them was discussed combined with the clinical and pathological parameters. Kruskal-Wallis test was used for the univariate correlation analyses and comparison of mutation rate and expression rate, and Chi-square test was used for the association of central lymph node metastasis with BRAF gene and TSHR. The BRAF ${ }^{\mathrm{V} 600 \mathrm{E}}$ mutation only existed in patients with thyroid cancer. The larger the number of metastatic central lymph nodes was, the higher the proportion of $\mathrm{BRAF}^{\mathrm{V} 600 \mathrm{E}}$ mutation would be. The $\mathrm{BRAF}^{\mathrm{V} 600 \mathrm{E}}$ mutation was related to the primary lesion size, capsular infiltration and lymph node metastasis of PTMC $(\mathrm{P}<0.05)$. The expression of TSHR in PTMC tissues was $<$ those in thyroid benign lesions and para-carcinoma normal tissues, which was positively associated with the central lymph node metastasis $(\mathrm{P}<0.05)$. The low expression of TSHR was related to the primary lesion size, capsular infiltration and metastatic lymph nodes of PTMC $(\mathrm{P}<0.05)$. The BRAF ${ }^{\mathrm{V} 600 \mathrm{E}}$ and TSHR may be involved in the occurrence and lymphatic metastasis of PTMC. The $\mathrm{BRAF}^{\mathrm{V} 600 \mathrm{E}}$ mutation has no association with the TSHR protein expression $(\mathrm{P}=0.256)$, but the coincidence coefficient indicates that their diagnostic significance in PTMC is not similar, so BRAF ${ }^{\mathrm{V} 600 \mathrm{E}}$ mutation and TSHR protein expression
\end{abstract}

Correspondence to: Dr Yang Zhang, Department of Thyroid and Breast Surgery, Liaocheng People's Hospital, 67 Dongchangxi Road, Liaocheng, Shandong 252000, P.R. China

E-mail: 13020572996@163.com

*Contributed equally

Key words: BRAF gene, TSHR, papillary thyroid microcarcinoma, central lymph node metastasis can be used jointly in the prediction of invasion and lymph node metastasis of PTMC, which may be more meaningful for clinical guidance.

\section{Introduction}

Thyroid cancer (TC) is one of the most common malignant endocrine and head-neck tumors $(1,2)$, as well as a malignant tumor with the most rapid increase in the incidence rate in recent years, with an annual average incidence rate of $6.2 \%$ (3), showing an increasing trend year by year (4). Research in China has indicated that the incidence rate of TC in the country is approximately $1 / 100,000-3 / 100,000$, accounting for $1.3-1.5 \%$ of that of all the malignant tumors (5). TC consists of three major pathological types: Differentiated (DTC), anaplastic (ATC) and medullary thyroid cancer (MTC), of which more than $90 \%$ of TC belongs to DTC. DTC can be further divided into two types, namely, papillary thyroid cancer (PTC) and follicular thyroid cancer (FTC) (6). Among the four pathological types, PTC is the most common, accounting for nearly $80 \%$ of the total cases of TC (7); in addition, it occurs in a wide age range, from 10 years to 100 years. With the progress of diagnostic technology and enhancement of prevention awareness, the incidence rate of papillary thyroid microcarcinoma (PTMC) is increased significantly, which has been reported by experts and scholars in the United States, Denmark, India and Germany (8-11). PTMC refers to the papillary thyroid carcinoma with a diameter $\leq 10 \mathrm{~mm}$ (12). It was believed previously that PTMC has a lower invasiveness of primary lesion $(13,14)$. However, recent studies have shown that PTMC cases, manifested as local tissue invasion and cervical (central and lateral cervical areas) lymph node metastasis, are increasing (15). After sorting out and analyzing clinical data, the experts found that PTMC is not an early cancer (16).

During the investigation of tumor occurrence and development, many experts and scholars agree that tumor is a multi-stage, multi-factor and multi-gene biological phenomenon. BRAF gene is currently considered as one of the most important papillary thyroid carcinoma (PTC) driver genes, and a large number of studies have confirmed that the occurrence of PTC is mainly due to the activation of RAS-RAF-MEK-MAPK pathway caused by BRAF ${ }^{\mathrm{V} 600 \mathrm{E}}$ mutation, RET/PTC rearrangement and RAS gene mutation, 
thus leading to the occurrence of malignant tumors (17-19) (Fig. 1). Therefore, the $\mathrm{BRAF}^{\mathrm{V} 600 \mathrm{E}}$ mutation is closely related to the invasiveness of PTC, including primary lesion breaking through the capsule, cervical lymph node metastasis or distant metastasis and tumor progression $(20,21)$. In recent studies, there have been more and more studies on BRAF gene mutation and PTC, but few studies on the association between $\mathrm{BRAF}^{\mathrm{V} 600 \mathrm{E}}$ mutation and PTMC. Therefore, the investigation of expression of $\mathrm{BRAF}^{\mathrm{V} 600 \mathrm{E}}$ mutation in PTMC and the association analyses combined with its clinical parameters have important guiding significance in the clinical diagnosis and treatment of PTMC patients.

Thyroid-stimulating hormone receptor (TSHR) is a macromolecule glycoprotein, mainly located in the thyroid follicular epithelial cell membrane, whose main functions are to regulate and control the growth and differentiation of thyroid cells. In recent years, studies in China have found that the primary papillary thyroid carcinoma (PTC) metastasis is accompanied with the TSHR expression; some thyroid-related diseases are caused by abnormal TSHR expression (22). It has been proven that TSHR is completely expressed in normal thyroid tissues, and that it is expressed for $86.7 \%$ in papillary cancer and $23.8 \%$ in ATC. The normal thyroid tissues can be distinguished from PTC with varied differentiations through different TSHR expressions, of which the expression level is positively correlated with the degree of differentiation $(23,24)$. Some scholars measured the expression of TSHR in paraffinembedded specimens collected from primary PTC using immunohistochemical method (AP method), and the results showed that the positive expression rate of TSHR in highly differentiated PTC is $<$ that in typicalPTC. Therefore, the TSHR expression has a negative association with the differentiation and invasiveness of PTC (25). Chen et al measured the TSHR in PTC and normal thyroid tissues through AP method (22). It was revealed that the positive expression rate of TSHR in PTC tissues is similar to that in normal thyroid tissues; in PTC tissues; the TSHR expression level is related to tumornode-metastasis (TNM) staging and lymph node metastasis of the neck, while it is not correlated with sex, age and other factors. Meanwhile, TSHR is highly expressed in PTC patients with high differentiation, low invasiveness and no lymph node metastasis $(26,27)$. There have been few studies on the TSHR expression in PTMC.

How are BRAF ${ }^{\mathrm{V} 600 \mathrm{E}}$ mutation and TSHR expression related to PTMC? What are the BRAF gene mutation rate and TSHR expression in highly invasive PTMC? Can BRAF gene and TSHR be used as markers for evaluating the PTMC invasion before operation? In the present study, the tissue specimens and clinicopathologic data of 162 PTMC patients in the Department of Thyroid and Breast Surgery of Liaocheng People's Hospital (Liaocheng, China) were collected and treated. The BRAF ${ }^{\mathrm{V} 600 \mathrm{E}}$ mutation frequency and TSHR expression were detected via qPCR and immunohistochemical method, and the association among parameters were studied to find indexes that can predict the local tissue invasion and cervical lymph node metastasis potential of PTMC, evaluate the patients before operation in a comprehensive and scientific manner, select the reasonable and accurate surgical methods during operation and provide individualized diagnosis and treatment support for patients.

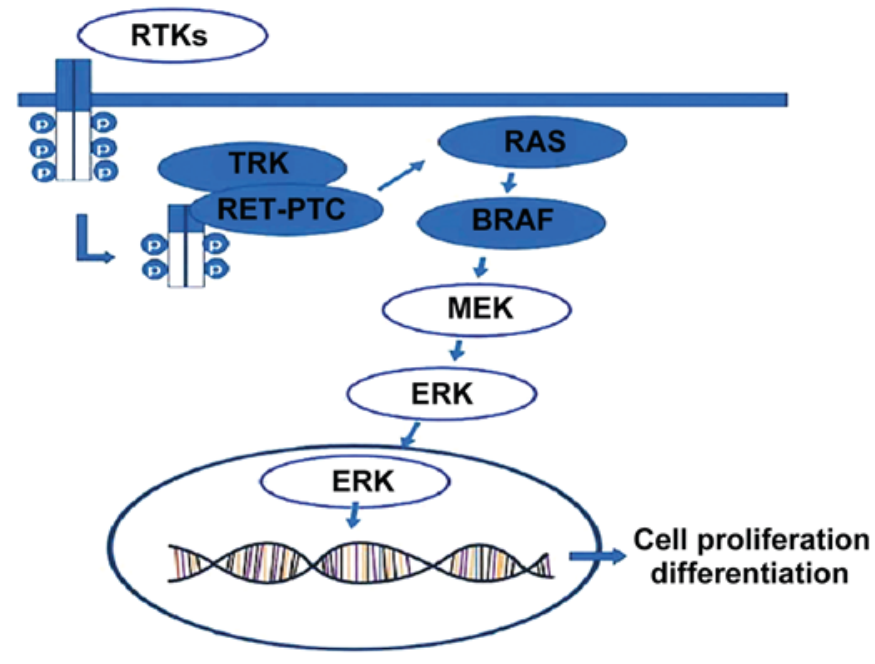

Figure 1. Renin-angiotensin system/RAF/MEK/extracellular signal-regulated kinase (RAS/RAF/MEK/ERK) pathways.

\section{Patients and methods}

Inclusion criteria. In the present study, TC patients receiving operation in the Department of Thyroid Breast Surgery of Liaocheng People's Hospital from September 1, 2015 to August 31, 2016 were selected. The serum free triiodothyronine (free T3), free thyroxine (free T4), TSH, thyroid peroxidase antibody (TPOAB) and thyroglobulin antibody (TGAb) in all patients were measured via radio-immunity determination after admission, so as to exclude the effect of PTMC combined with Hashimoto's thyroiditis on the research results. Objects enrolled had to meet the following requirements: i) First visit, no history of thyroid-related diseases and medications due to thyroid diseases; ii) no history of Grave's disease, no history of present illness or past medical history of malignant tumors; iii) complete clinical data; well-preserved paraffin-embedded specimens of thyroid cancer and cervical lymph nodes in the Pathology Department; iv) total resection of affected lobes + total resection of contralateral lobes + central and (or) cervical lymph node dissection performed in Thyroid Surgery of hospital; v) TC diagnosed via preoperative fine-needle aspiration pathocytology, intraoperative rapid pathology and postoperative routine pathology; and iv) not a large number of calcifications in primary lesions. The study was approved by the Ethics Committee of Liaocheng People's Hospital and written informed consents were signed by the patients or the guardians.

During the above period, a total of 610 cases of PTC treated in thyroid surgery via operation were selected, among which 357 cases had cervical lymph node metastasis. There were a total of 293 cases of PTMC, including 161 cases with cervical lymph node metastasis. Those patients who were not treated for the first time, relapsed after TC operation in the past or underwent operation in our hospital after irregular operation in other hospital $(n=57)$, without complete clinical parameters or examinations (early cases, $\mathrm{n}=19$ ), with malignant tumors in other sites during treatment $(n=7)$, without complete primary lesion or cervical lymph node specimens of PTMC (patients receiving TC operation in another hospital, $n=24$ ), whose data were used for consultation and scientific research and not 


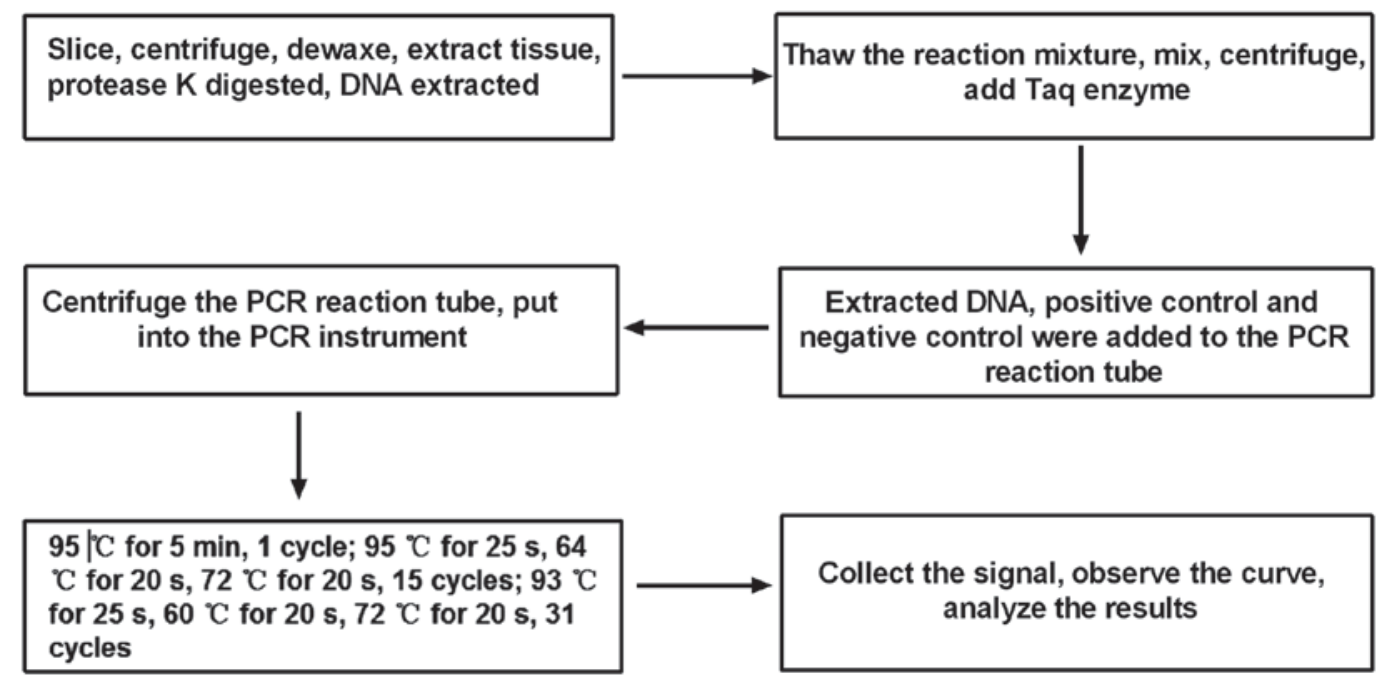

Figure 2. Detection process of $\mathrm{BRAF}^{\mathrm{VE} 600}$ mutation via $\mathrm{qPCR}$.

returned $(n=19)$, and experimental results that could not be judged $(n=5)$ were eliminated. As a result, a total of 162 cases were included.

Collection of pathological specimens and clinical data. Pathological specimens: A total of 162 paraffin-embedded specimens of primary PTMC cases meeting the requirements were collected. Thirty paraffin-embedded specimens of thyroid benign lesions and 30 paraffin-embedded specimens of para-carcinoma normal tissues in patients receiving operative treatment during the same period were selected as control group, respectively. All experimental specimens were provided by the Pathology Department of Liaocheng People's Hospital.

The following clinical parameters of 162 PTMC patients were recorded: Sex, age, pathological diagnosis, primary lesion size, primary lesion and cervical lymph node operation methods, subsequent treatment, tumor diameter, the number of TC lesions, the number of central and lateral cervical metastatic lymph nodes, metastasis rate, and primary tumor breaking through the capsule.

\section{Treatment methods}

Treatment principle of primary lesion. Patients who were diagnosed with single foci or unilateral multiple tumor via imaging before operation usually received the total resection of lobes and isthmus on the affected side. Those with multiple tumor in bilateral lobes (including the isthmus) were treated with the total resection of double lobes + isthmus resection.

Treatment principle of cervical lymph nodes. Frozen biopsy of primary lesion was performed during operation, and those diagnosed with PTMC were treated with central (VI area) lymph node dissection at least. According to the preoperative imaging examination of the lateral cervical lymph node formation combined with intraoperative exploration, those diagnosed with lateral cervical (II-IV area) lymph node $\mathrm{cN}^{+}$ were treated with lateral cervical lymph node dissection.

Test methods. The qualified primary lesion of PTMC, thyroid benign mass and para-carcinoma normal tissues were taken from the Pathology Department and cut into $4 \mu \mathrm{m}$-thick sections. The primary lesion was confirmed to be positive. The $\mathrm{BRAF}^{\mathrm{V} 600 \mathrm{E}}$ gene detection and immunohistochemical staining of TSHR protein [the positive pathological section was used as the positive staining control, and phosphate buffered saline (PBS), instead of the first antibody, was used as negative control] were performed in the primary lesion of PTMC, thyroid benign mass and para-carcinoma normal tissues by senior physicians in the Pathology Department.

\section{Main steps of gene detection}

DNA extraction of paraffin-embedded tissues. Six to eight pieces of 5-10 $\mu \mathrm{m}$ paraffin-embedded tissue specimens were taken and placed into a $1.5 \mathrm{ml}$ Eppendorf tube, added with $1.0 \mathrm{ml} x y l e n e$, incubated at $60^{\circ} \mathrm{C}$ for $10 \mathrm{~min}$, and centrifuged at $12,000 \mathrm{x} g$ at room temperature for $3 \mathrm{~min}$, and the supernatant was discarded (cross contamination of specimen should be avoided). Anhydrous ethanol $(1.0 \mathrm{ml})$ was added into the tube, mixed upside down evenly at room temperature for $10 \mathrm{sec}$, and centrifuged at $12,000 \mathrm{x}$ g for $3 \mathrm{~min}$, and the supernatant was discarded. The above steps were repeated 2 times. The tube cover was opened, and the remaining anhydrous ethanol was dried at $55^{\circ} \mathrm{C}$ cleavage.

A total of $400 \mu 1$ supporting GT buffer and $20 \mu 1$ proteinase $\mathrm{K}(10 \mathrm{mg} / \mathrm{ml})$ were added into the treated tissues and mixed evenly. The mixture was digested at $56^{\circ} \mathrm{C}$ for $90 \mathrm{~min}$ or overnight, until the specimens were completely cleaved. The specimens were incubated at $90^{\circ} \mathrm{C}$ for $30 \mathrm{~min}$, followed by high-speed centrifugation to collect the liquid on the wall. The supernatant was transferred into the supporting ultrafiltration tube, followed by centrifugation at $12,000 \mathrm{x} \mathrm{g}$ for $5 \mathrm{~min}$. The clean tissue mixture after centrifugation was transferred into the matching sample tube. The sample tube was put in place; in the fourth track of frame using the program code of 401. After the extraction, DNA was placed in a refrigerator at $-20^{\circ} \mathrm{C}$ for standby application.

$q P C R$. The reaction mixture was thawed at room temperature, and mixed evenly on a vortex vibrator for $15 \mathrm{sec}$, followed by high-speed centrifugation at $12,000 \mathrm{xg}$ for $15 \mathrm{sec}$ at $4^{\circ} \mathrm{C}$. 


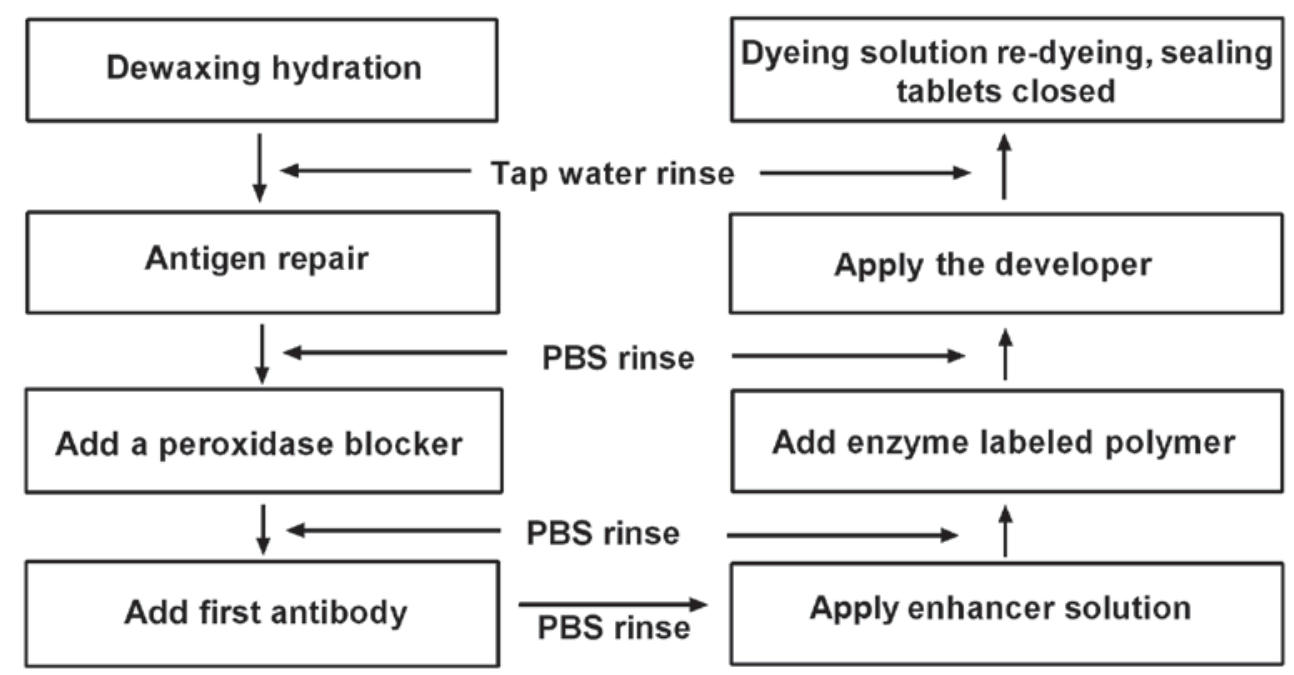

Figure 3. Detection process of TSHR protein expression via immunohistochemical method.

A total of $35 \mu 1$ reaction mixture in each tube was mixed with $0.4 \mu 1$ Taq enzyme. Reaction mixture with Taq enzyme (35 $\mu 1)$ was placed into the PCR tube. DNA sample $(5 \mu 1)$ to be tested (with following concentration), positive and negative control were added into the PCR tube. The DNA concentration of paraffin sections was recommended to be $2-3 \mathrm{ng} / \mu \mathrm{l}$. The PCR tube was centrifuged to gather the reagent into the bottom of tube, and then the PCR tube was placed onto the real-time PCR instrument. The setup window was opened for setting according to the amplification procedure chart in the picture below. Stage 1: $95^{\circ} \mathrm{C}$ for $5 \mathrm{~min}, 1$ cycle. Stage 2: $95^{\circ} \mathrm{C}$ for $25 \mathrm{sec}, 64^{\circ} \mathrm{C}$ for $20 \mathrm{sec}, 72^{\circ} \mathrm{C}$ for $20 \mathrm{sec}, 15$ cycles. Stage 3: $93^{\circ} \mathrm{C}$ for $25 \mathrm{sec}, 60^{\circ} \mathrm{C}$ for $20 \mathrm{sec}, 72^{\circ} \mathrm{C}$ for $20 \mathrm{sec}$, 31 cycles. Signal collection: FAM and HEX (or VIC) signals were collected in Stage 3 at $60^{\circ} \mathrm{C}$, the qPCR was performed and the files were saved (Fig. 2).

Main steps of immunohistochemical method. Each batch of samples was stained in strict accordance with reagent instructions.

\section{Preparation}

Baking. The sections of positive control tissues and tissues to be tested were baked in an incubator at $68^{\circ} \mathrm{C}$ for $120 \mathrm{~min}$. Dewaxing via xylene was carried out: Thick paraffin sections (4 $\mu \mathrm{m})$ were dewaxed using grade I, II and III xylene for 5 min.Hydration: Sections were hydrated using anhydrous ethanol, 95 and 80\% ethanol for 3 min and washed with PBS 3 times ( $3 \mathrm{~min} /$ time).

Antigen retrieval. High-pressure heat retrieval: The slide was placed on a heat-resistant staining rack, and added with $0.01 \mathrm{M}$ boiled sodium citrate buffer solution. The stainless steel pressure cooker lid and pressurizing valve were covered. At $2 \mathrm{~min}$ after air injection, the pressure cooker lid was opened, and the slide was washed with PBS after natural rewarming.

Immunohistochemical staining. Immunohistochemical PAP pen was used to draw circles at $0.5 \mathrm{~cm}$ away from the tissue border. Hydrogen peroxide solution (3\%) was dropwise added onto each slide for incubation at room temperature for $10 \mathrm{~min}$ to block the endogenous peroxidase. Then the slice was washed with PBS for 3 min $x 3$ times. PBS was shaken off, and appropriate amount of primary antibody rabbit polyclonal to TSHR (ab 202960; 1:1,000; Abcam, Cambridge, MA, USA) was dropwise added onto each slide in a refrigerator at $4^{\circ} \mathrm{C}$ for $12 \mathrm{~h}$. Then the slide was washed with PBS for 5 min $x 3$ times. Appropriate amount of biotin-labeled goat anti-rabbit immunoglobulin G (IgG) (cat. no. sc-2004; 1:3,000; Santa Cruz Biotechnology, Inc. Santa Cruz,CA, USA) was dropwise added onto each slide, followed by incubation at room temperature for $20 \mathrm{~min}$. Then the slide was washed with PBS for 3 min $x 3$ times. PBS was shaken off, and horseradish peroxidase-labeled streptavidin working solution was added, followed by incubation at room temperature for $30 \mathrm{~min}$. Then the slide was washed with PBS for 3 min x 3 times. PBS was shaken off, and appropriate amount of freshlyprepared diaminobenzidine (DAB) was dropwise added onto each slide, the color development time was controlled under the microscope (Olympus Corporation, Tokyo, Japan). No background staining and strong staining in positive parts prevailed. Brown staining indicated positive. The slice was washed with tap water, re-stained using hematoxylin for $5 \mathrm{~min}$, differentiated via $0.1 \mathrm{ml}$ hydrochloric acid alcohol, and washed again with tap water, followed by dehydration using 80, 95 and 100\% anhydrous ethanol, and transparent treatment via grade I, II and III xylene. The slide was sealed using the automatic sealing machine (Fig. 3).

\section{Determination of results}

Determination of gene detection results. The curves in the saved files were observed. If the cycle threshold $(\mathrm{Cq})$ value of carboxy fluorescein (FAM) signal of specimen was $\geq 28$, the sample was negative (or it was lower than the lower detection limit of kit). If the $\mathrm{Cq}$ value of FAM signal was $<28$, the sample was positive.

Determination of immunohistochemical results. Double-blind method was used to determine the immunohistochemical results. All the experimental results were interpreted by senior 
Table I. Clinicopathological data of 162 PTMC patients.

\begin{tabular}{lr}
\hline Clinical parameter & $\mathrm{n}(\%)$ \\
\hline Age (years) & \\
$\geq 45$ & $101(62.3)$ \\
$<45$ & $61(37.7)$ \\
Sex & \\
Male & $31(19.1)$ \\
Female & $131(81.9)$ \\
Tumor diameter & \\
$\leq 5$ mm & $101(62.3)$ \\
$>5$ mm and $\leq 10$ mm & $61(37.7)$ \\
Single or multiple lesion & \\
Single & $45(27.8)$ \\
Multiple & $117(72.2)$ \\
TNM staging & \\
I/II & $110(67.9)$ \\
III/IV & $52(32.1)$ \\
Capsular infiltration & \\
Yes & $119(73.5)$ \\
No & $43(26.5)$ \\
Central lymph node metastasis & \\
Yes & \\
$>3$ & $24(14.8)$ \\
$\leq 3$ & $61(37.7)$ \\
No & $77(47.50$ \\
Lateral cervical lymph node metastasis \\
Yes & \\
No & \\
\hline & \\
& \\
& \\
&
\end{tabular}

physicians in the Pathology Department, and no clinical parameters of patients were not provided for physicians. In principle, the membrane structure after cancerization will lead to the dispersion and incorrect positioning of dyeing agent, so the cell membrane staining may also cause cytoplasmic staining, but it may be more meaningful for the expression level on the cell membrane. Under an optical microscope (Olympus Corporation), the brown yellow-stained cell membrane and cytoplasm indicated positive cells. TSHR protein was mainly located in the cell capsule, and some were located in the cytoplasm. Cell membrane and cytoplasm were stained pale yellow, and gradually became dark brown with the increase in staining strength.

Determination of cell staining intensity and percentage of positive cells under an optical microscope (Olympus Corporation). Scoring criteria of cell staining intensity: no staining: 0 point, negative (-); pale yellow: 1 point, weakly positive (+); brown yellow: 2 points, moderately positive $(++)$; dark brown: 3 points, strongly positive.

Scoring criteria of positive cell percentage. The experimental specimens were placed under a high-power microscope (Olympus Corporation), five non-coincident fields of view
Table II. Comparison of mutation rate between PTMC and control group.

\begin{tabular}{lrcc}
\hline & \multicolumn{3}{c}{ BRAF gene } \\
\cline { 2 - 4 } Groups & $\begin{array}{c}\text { Mutant } \\
\text { type }\end{array}$ & $\begin{array}{c}\text { Wild- } \\
\text { type }\end{array}$ & $\begin{array}{c}\text { Mutation } \\
\text { rate \% }\end{array}$ \\
\hline PTMC & 135 & 27 & 83.3 \\
Thyroid benign lesion & 0 & 30 & 0 \\
Para-carcinoma normal tissue & 0 & 30 & 0 \\
\hline
\end{tabular}

(x400) were randomly selected, and 100 cells were counted in each field of view. The positive cells were counted and the percentage of positive cells was calculated. The percentage of positive cells $<5 \%, 0$ point (-); $5-25 \%, 1$ point (+); 25-50\%, 2 points $(++) ; \geq 50 \%, 3$ points $(+++)$.

Comprehensive immunohistochemical measurement criteria. In order to avoid the experimental errors caused by ranges of cell staining strength and percentage of positive cells, semiquantitative assessment was performed using cell staining strength and percentage of positive cells. The two scores were multiplied: A total score of 5 points and above: Strongly positive (+++); 3-4 points: Moderately positive $(++)$; $1-2$ points: Weakly positive $(+)$; 0 point: Negative. The results with more than 3 points indicated high expression, while those with $0-3$ points indicated low expression.

Statistical analysis. The experimental data were analyzed using Statistical Product and Service Solutions (SPSS) 20.0 (IBM Corp., Armonk, NY, USA) software. Enumeration data were presented as a case. Kruskal-Wallis test was used for the univariate correlation analyses and comparisons of mutation rate and expression rate, and Chi-square test was used for the associations of central lymph node metastasis with BRAF gene and TSHR. $\mathrm{P}<0.05$ indicates that the difference was statistically significant.

\section{Results}

Clinical and pathological data. The 162 PTMC patients were aged 24-69 years with an average of 46.37 years. There were 31 male and 131 female patients (male/female ratio: 1:4.2). The total resection of lobes and isthmus on the affected side + total resection of contralateral lobes + central and lateral cervical lymph node dissection were performed (Table I).

\section{$B R A F$ gene expression}

Detection results of $B R A F^{V E 600}$ mutation. There were 135 cases of BRAF ${ }^{\mathrm{VE} 600}$ mutation in 162 cases of primary lesion of PTMC, accounting for $83.3 \%$. Thirty cases of thyroid benign lesions and 30 cases of para-carcinoma normal tissues had no mutation. The mutant-type and wild-type BRAF and control group detected via qPCR are shown in Figs. 4 and 5 and Table II.

Univariate analyses of BRAF gene expression and clinical parameters of PTMC. Among 135 cases of BRAF ${ }^{\mathrm{VE} 600}$ 


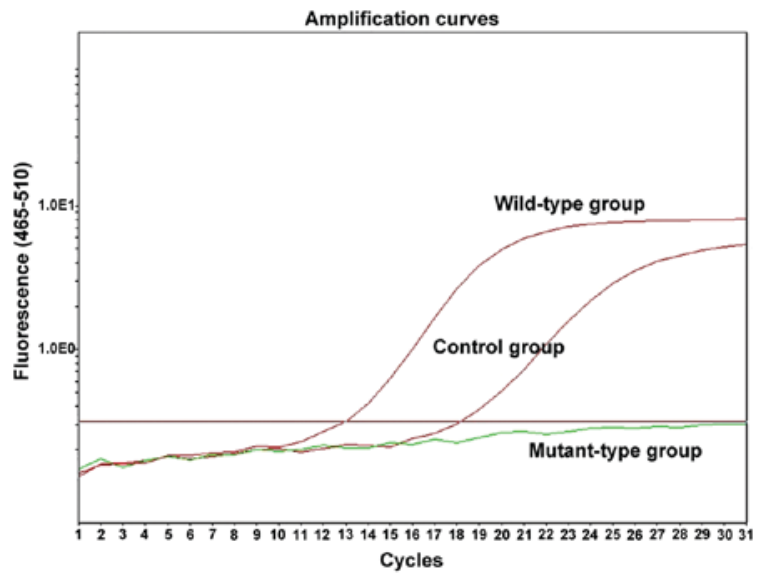

Figure 4. BRAF gene mutation curve.

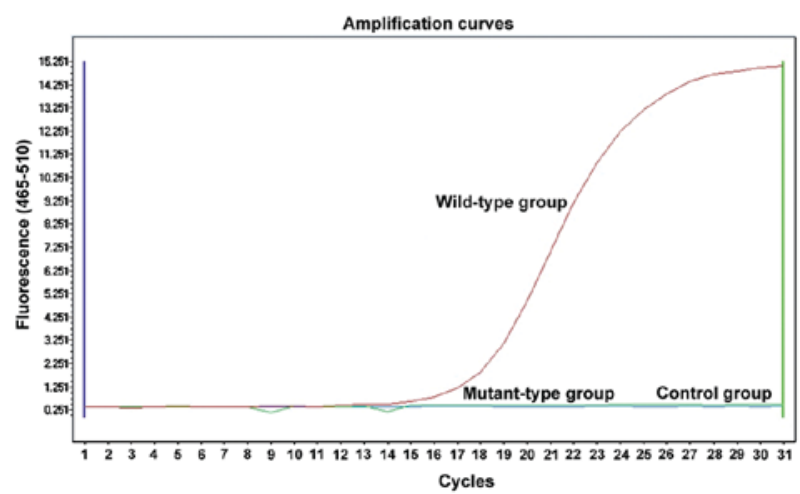

Figure 5. Curves of wild-type BRAF gene, thyroid benign lesion and negative para-carcinoma tissues.

mutation in 162 cases of primary lesion of PTMC, there were 26 male patients and 109 female patients. Eighty-five cases of lymph node metastasis were found in the 162 cases of cervical lymph node dissection, and the remaining 77 cases had no lymph node metastasis. Eighty-five cases had the central lymph node metastasis, including 44 cases of lateral cervical lymph node metastasis and 41 cases without metastasis. No distant metastasis was found in the patients (Table III).

Analysis of association between BRAF gene mutation and central lymph nodes. Based on the central lymph nodes, Table III, it could be seen that the sample size was still relatively small after grouping, and it was difficult to use the rank test in pairwise analyses. The results of Chi-square test for trend showed that the larger the number of metastatic central lymph node was, the higher the proportion of mutant type would be, and the larger the probability of mutation would also be (trend $\chi^{2}=5.704, \mathrm{P}=0.017$ ).

\section{TSHR expression}

TSHR detection results. Among 162 cases of primary lesion of PTMC, there were 92 cases of low expression TSHR (56.8\%) and 70 cases of high expression TSHR (including the normal expression with 4 points; $43.2 \%$ ). The normal expression of 30 cases of thyroid benign lesions and 30 cases of paracarcinoma normal tissues were used as the control. The high

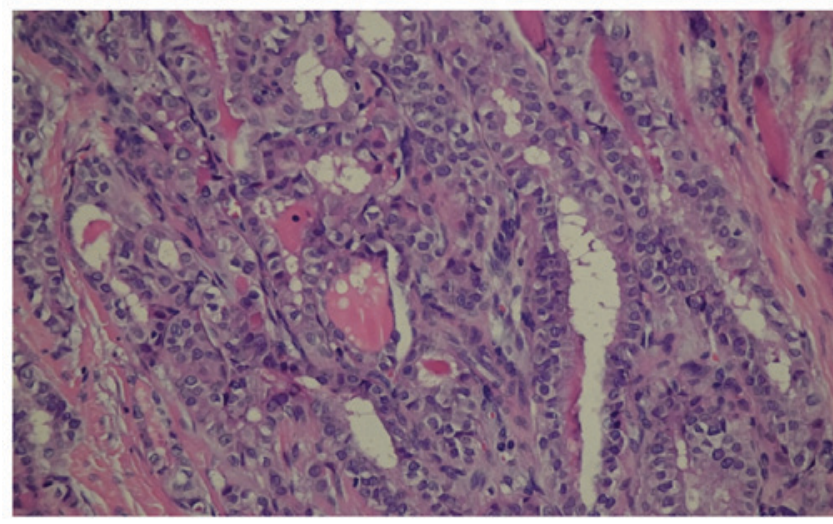

Figure 6. PTMC tissues without immunohistochemical staining (magnification, $\mathrm{x} 400)$.

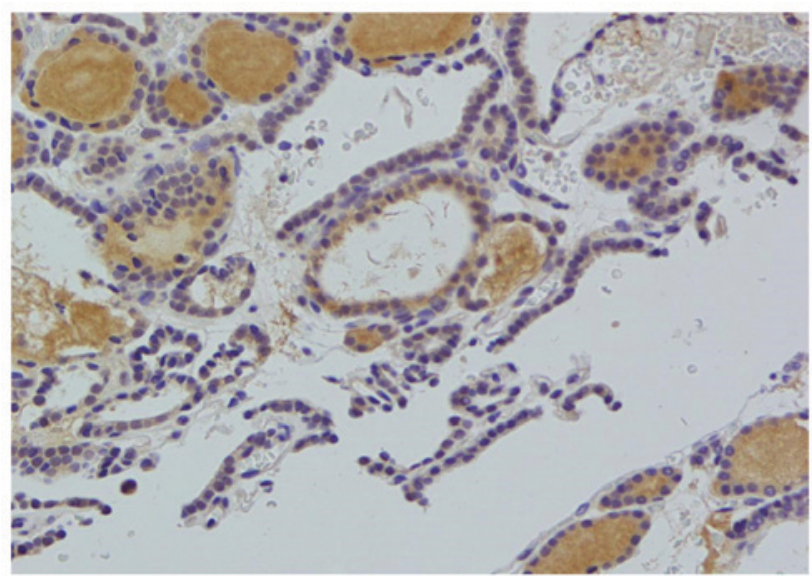

Figure 7. TSHR protein expressions in thyroid benign lesion and paracarcinoma tissues (magnification, $\mathrm{x} 400$ ).

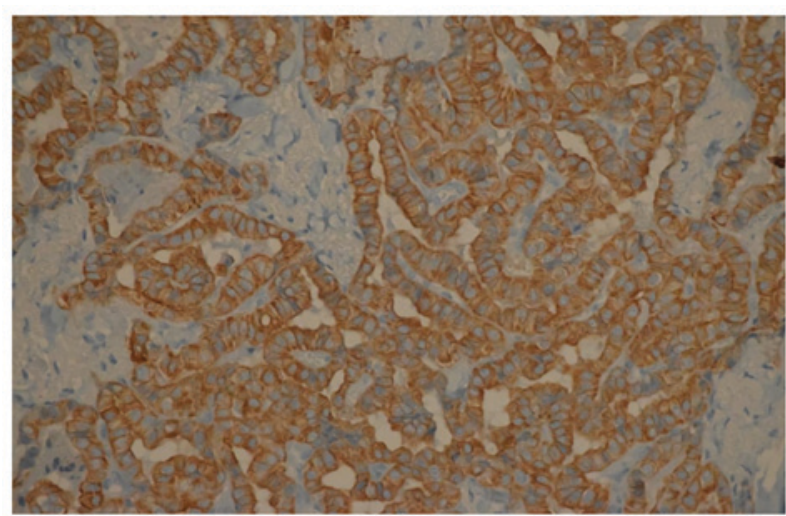

Figure 8. Low expression of TSHR protein in PTMC (magnification, $\mathrm{x} 400$ ).

and low expression of TSHR and normal expression in control group detected via immunohistochemical method are shown in Figs. 6-9 and Table IV.

Univariate analyses of TSHR expression and clinical parameters of PTMC. The normal expression of TSHR in control group was used as a reference standard; 0-3 points in 162 cases of primary lesion of PTMC indicated low expression, while greater than 3 points indicated high expression (Table V). 
Table III. Univariate analyses of BRAF gene expression and clinical parameters in PTMC group.

\begin{tabular}{|c|c|c|c|c|c|}
\hline \multirow[b]{2}{*}{ Clinical parameter } & \multirow[b]{2}{*}{ No. } & \multicolumn{2}{|c|}{ BRAF gene expression } & \multirow[b]{2}{*}{$\chi^{2}$ value } & \multirow[b]{2}{*}{ P-value } \\
\hline & & Mutant type & Wild-type & & \\
\hline Age (years) & & & & 0.636 & $0.452^{\mathrm{b}}$ \\
\hline$\geq 45$ & 101 & 86 & 15 & & \\
\hline$<45$ & 61 & 49 & 12 & & \\
\hline Sex & & & & 0.282 & $0.596^{\mathrm{b}}$ \\
\hline Male & 31 & 26 & 5 & & \\
\hline Female & 131 & 109 & 22 & & \\
\hline Tumor diameter & & & & 5.054 & $0.025^{\mathrm{a}}$ \\
\hline$\leq 5 \mathrm{~mm}$ & 101 & 79 & 22 & & \\
\hline$>5 \mathrm{~mm}$ and $\leq 10 \mathrm{~mm}$ & 61 & 56 & 5 & & \\
\hline Single or multiple lesion & & & & 0.055 & $0.814^{\mathrm{b}}$ \\
\hline Single & 45 & 37 & 8 & & \\
\hline Multiple & 117 & 98 & 19 & & \\
\hline TNM staging & & & & 0.566 & $0.452^{\mathrm{b}}$ \\
\hline $\mathrm{I} / \mathrm{II}$ & 110 & 90 & 20 & & \\
\hline III/IV & 52 & 45 & 7 & & \\
\hline Capsular infiltration & & & & 3.948 & $0.047^{\mathrm{a}}$ \\
\hline Yes & 119 & 104 & 15 & & \\
\hline No & 43 & 32 & 11 & & \\
\hline Central lymph node metastasis & & & & 6.520 & $0.038^{\mathrm{a}}$ \\
\hline Yes & & & & & \\
\hline$>3$ & 24 & 23 & 1 & & \\
\hline$\leq 3$ & 61 & 53 & 8 & & \\
\hline No & 77 & 59 & 18 & & \\
\hline Lateral cervical lymph node metastasis & & & & 5.491 & $0.019^{\mathrm{a}}$ \\
\hline Yes & 44 & 42 & 2 & & \\
\hline No & 41 & 33 & 9 & & \\
\hline
\end{tabular}

${ }^{\mathrm{a}} \mathrm{P}<0.05$, statistical significance; ${ }^{\mathrm{b}} \mathrm{P}>0.05$, no statistical significance.

Analysis of association between TSHR expression and central lymph node. It could be seen from the data grouping in Fig. 4 that the rank test of pairwise comparison was less meaningful. The results of Chi-square test for trend showed that the higher the number of metastatic central lymph node was, the higher the proportion of low expression would be, and the larger the probability of low expression would also be (trend $\chi^{2}=11.036$, $\mathrm{P}=0.001)$.

Association between BRAF ${ }^{V E 600}$ mutation and TSHR expression in PTMC group. BRAF gene detection and TSHR expression detection were successfully performed for 162 cases of primary lesion of PTMC. There were 135 cases of BRAF gene mutation, including 74 cases of low expression TSHR and 61 cases of high expression TSHR. There were 27 cases of wild-type BRAF gene, including 18 cases of low expression TSHR and 9 cases of high expression TSHR (Table VI).

The coincidence coefficient of the two methods was $\mathrm{K}=0.06(\mathrm{P}=0.256)$; the coincidence rate was $51.2 \%$.

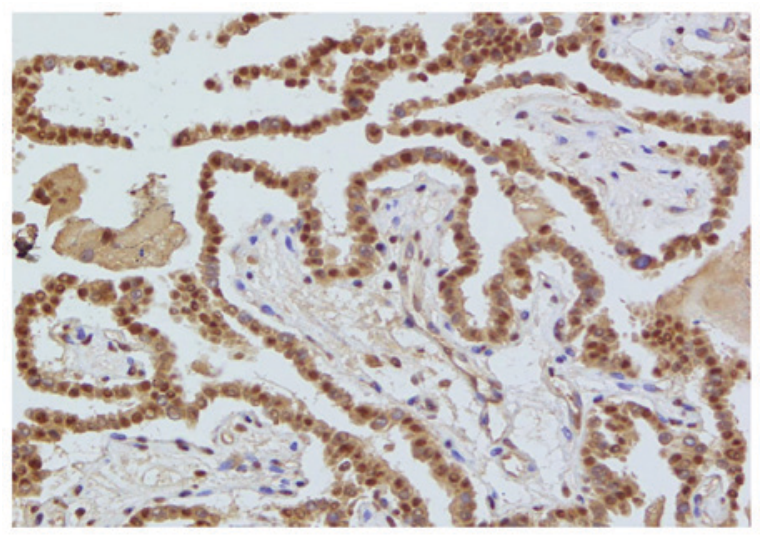

Figure 9. High expression of TSHR protein in PTMC (magnification, x400).

\section{Discussion}

As one of the most common malignant tumors in the Head-Neck Surgery Department and Endocrine Department (28), 
Table IV. Comparison of expression level between PTMC and control group.

TSHR

\begin{tabular}{lccc}
\cline { 2 - 4 } Groups & Low expression & Normal expression & High expression \\
\hline PTMC & 92 & 0 & 70 \\
Thyroid benign lesion & 0 & 30 & 0 \\
Para-carcinoma normal tissue & 0 & 30 & 0
\end{tabular}

The score in PTMC group is 4 points, suggesting the high expression.

Table V. Univariate analyses of TSHR expression and clinical parameters of PTMC in PTMC group.

\begin{tabular}{|c|c|c|c|c|c|}
\hline \multirow[b]{2}{*}{ Clinical parameter } & \multirow[b]{2}{*}{ No. } & \multicolumn{2}{|c|}{ TSHR expression } & \multirow[b]{2}{*}{$\chi^{2}$} & \multirow[b]{2}{*}{ P-value } \\
\hline & & Low expression & High expression & & \\
\hline Age (years) & & & & 0.044 & $0.834^{\mathrm{b}}$ \\
\hline$\geq 45$ & 101 & 58 & 43 & & \\
\hline$<45$ & 61 & 34 & 27 & & \\
\hline Sex & & & & 0.025 & $0.873^{\mathrm{b}}$ \\
\hline Male & 31 & 18 & 13 & & \\
\hline Female & 131 & 74 & 57 & & \\
\hline Tumor diameter & & & & 4.332 & $0.037^{\mathrm{a}}$ \\
\hline$\leq 5 \mathrm{~mm}$ & 101 & 51 & 50 & & \\
\hline$>5 \mathrm{~mm}$ and $\leq 10 \mathrm{~mm}$ & 61 & 41 & 20 & & \\
\hline Single or multiple lesion & & & & 0.819 & $0.366^{\mathrm{b}}$ \\
\hline Single & 45 & 23 & 22 & & \\
\hline Multiple & 117 & 69 & 48 & & \\
\hline TNM staging & & & & 0.351 & $0.06^{\mathrm{b}}$ \\
\hline $\mathrm{I} / \mathrm{II}$ & 110 & 68 & 42 & & \\
\hline III/IV & 52 & 24 & 28 & & \\
\hline Capsular infiltration & & & & 5.371 & $0.021^{\mathrm{a}}$ \\
\hline Yes & 119 & 74 & 45 & & \\
\hline No & 43 & 18 & 25 & & \\
\hline Central lymph node metastasis & & & & 11.157 & $0.004^{\mathrm{a}}$ \\
\hline Yes & & & & & \\
\hline$>3$ & 24 & 19 & 5 & & \\
\hline$\leq 3$ & 61 & 39 & 22 & & \\
\hline No & 77 & 34 & 43 & & \\
\hline Lateral cervical lymph node metastasis & & & & 4.158 & $0.041^{\mathrm{a}}$ \\
\hline Yes & 44 & 29 & 15 & & \\
\hline No & 41 & 18 & 23 & & \\
\hline
\end{tabular}

${ }^{a} \mathrm{P}<0.05$, statistical significance; ${ }^{b} \mathrm{P}>0.05$, no statistical significance.

thyroid cancer (TC) is a malignant tumor with the most rapid increase in the incidence rate in recent ten years. There are approximately 120,000 cases of TC newly diagnosed worldwide every year (29), of which PTMC is especially significant. The reported 10-year survival rate of PTC is nearly $97 \%$ (30). As the most common subtype of PTC, PTMC with a primary lesion diameter of $\leq 10 \mathrm{~mm}$ is generally difficult to be discovered by the patients themselves due to its small volume and occult onset, and the disease can only be discovered in the patients receiving clinical diagnosis and treatment mainly through confirmed pathological findings obtained from ultrasound examination combined with fine-needle aspiration biopsy (FANB). With the 
Table VI. Relationship between BRAF ${ }^{\mathrm{VE} 600}$ mutation and TSHR expression in PTMC group.

TSHR

\begin{tabular}{lccccc}
\cline { 2 - 5 } Groups & Low expression & High expression & Total & P-value & K (coincidence coefficient) \\
\hline BRAF gene & 74 & 61 & 135 & $0.256^{\mathrm{a}}$ & 0.06 \\
Mutant type & 18 & 9 & 27 & & \\
Wild-type & 70 & 92 & 162 & & \\
Total & & 92 & & \\
\hline
\end{tabular}

${ }^{a} \mathrm{P}>0.05$, no statistical significance.

improvement of examination techniques, more and more cases of PTMC are discovered, whose detection rate is remarkably higher than that of other types of TC $(30,31)$. However, it is possible that ultrasound examination is not popularized among teenagers, so the patients who have been diagnosed with PTMC so far are generally aged over 18 years. According to the research findings of American scholars, PTMC has become the most common malignant tumor among patients aged more than 45 years in the USA (32). The clinical biological characteristics of PTMC are moderate, and it may even have no effect on some patients for the whole life. But PTMC is still associated with higher central and cervical lymph node metastases. Studies have confirmed $(12,32-34)$ that the lymph node metastasis rate of PTMC is $48.1 \%$, the mortality rate is $0-0.4 \%$, and the recurrence and metastasis rate is $3.3 \%$. Most scholars have agreed that the microcarcinoma is not the early cancer. Due to the contradiction of good prognosis and high transfer rate, there has been no complete consensus on PTMC surgical treatment in different countries and different scholars. In particular, the surgical treatment of cervical lymph nodes is controversial. How to allow PTMC patients to receive more accurate treatment and determine the lymph node metastasis before operation is one of the urgent problems to be solved. In addition to improving the imaging diagnosis and using FANB cytological pathological results $(35,36)$ to identify the cytological pathological diagnosis levels for tumor differentiation level, searching the genes or molecular markers for PTMC invasion is also feasible.

BRAF gene is currently recognized as one of the most important PTC driver genes, also known as rodent sarcoma viral pathogen carcinogen homologue B1, which was first discovered and cloned by Ikawa et al (37) in 1988 in Ewing's sarcoma. Moreover, it is also an important gene in the RAS-RAF-MEK-MAPK signal transduction process, which mainly plays an important role in regulating cell growth, division and proliferation. The BRAF gene is located on human chromosome $7 \mathrm{q} 34$ and contains 18 exons. T mutation into A on the nucleotide 1799 replaces the corresponding valine to the 600th codon in protein translation with glutamic acid, increasing the kinase activity by approximately 500 times compared with the wild-type (negative), transmitting the signals to downstream MAPK pathway, and stimulating cells to produce mitosis and form malignant tumors $(38,39)$. Bansal et al (40) demonstrated that the mutation of BRAF ${ }^{\mathrm{V} 600 \mathrm{E}}$, as a proto-oncogene, affects the occurrence of PTC together with RET/PTC gene rearrangement and RAS gene mutation.
Jung et al (41) found that in recent classic PTC, the BRAF ${ }^{\mathrm{V} 600 \mathrm{E}}$ mutation rate is increased by $27 \%$, far exceeding the RET/ PTC gene rearrangement and RAS gene mutation. According to research $(42,43)$, the $\mathrm{BRAF}^{\mathrm{V} 600 \mathrm{E}}$ mutation rate is approximately $16-56 \%$ in PTMC, and approximately $23-80 \%$ in PTC. Therefore, BRAF gene has become the genetic mutation with the greatest significance in the diagnosis and treatment of PTMC, which is closely related to the occurrence and development of PTMC. BRAF gene mutation in PTMC may enhance the cell proliferation and transformation capacities. Studies have shown that (44) the detection rate of $\mathrm{BRAF}^{\mathrm{V} 600 \mathrm{E}}$ mutation in the lymph node infiltration and metastatic malignant tumors (clinical stage III/IV) is high, and it is related to the tumor size, capsular infiltration and other clinical factors, so the $\mathrm{BRAF}^{\mathrm{V} 600 \mathrm{E}}$ gene mutation is an index of predicting PTMC invasion.

In this experiment, it was found that 135 out of 162 cases of primary lesion of PTMC had BRAF ${ }^{\mathrm{V} 600 \mathrm{E}}$ mutation, accounting for $83.3 \%$. The Chi-square test of BRAF gene showed that the BRAF ${ }^{\mathrm{V} 600 \mathrm{E}}$ mutation was associated with the size of primary lesion of PTMC, capsular infiltration and lymph node metastasis, but not related to the age, sex, tumor lymph nodes metastasis (TNM) staging and the number of primary lesions. In principle, the larger the primary lesion is, the higher the possibility of capsular infiltration or even breaking, lymph node metastasis and mutation will be, and the stronger the invasion will also be. Notably, this experiment showed that among 162 cases of cervical lymph node dissection, there were 85 cases of lymph node metastasis and 77 cases of no metastasis; furthermore, there were 85 cases of central lymph node metastasis, including 44 cases of lateral cervical lymph node metastasis and 41 cases of no metastasis. All patients with lymph node metastasis had cervical lymph node metastasis. The Chi-square test for trend showed that the larger the number of metastatic central lymph node was, the higher the proportion of mutant type would be, and the larger the probability of mutation would also be (trend $\chi^{2}=5.704, \mathrm{P}=0.017$ ). The above experimental results were consistent with those reported by Xing et al (21). Therefore, BRAF ${ }^{\mathrm{V} 600 \mathrm{E}}$ mutation can not only help distinguish between benign and malignant tumors, but also suggest the intensity of local invasion and lymph node metastasis of malignant tumors, providing biological significance for the high invasiveness of primary lesion of PTMC.

In recent years, studies have found that the metastasis of primary lesion of PTC is often accompanied by the change in 
TSHR expression. TSHR, as a macromolecule glycoprotein, is the main antigen of toxic diffuse goiter in the G-protein-coupled receptor superfamily, whose gene is located on 14q31 with a length of $60 \mathrm{~kb}$, containing 10 exons and 9 introns, encoding 764 amino acids. TSHR is mainly located on the thyroid follicular epithelial cell membrane, while some are located in the cytoplasm and outside the cells, and its main mechanism is to regulate and control the thyroid cell growth and differentiation. In principle, TSH binds to extracellular TSHR to regulate $\mathrm{Tg}$, TPOAB and sodium iodide transporters, and promote the thyroid hormone secretion and thyroid cell growth through the cyclic adenosine monophosphate (cAMP) pathway (45); moreover, it also indirectly promotes the synthesis of thyroid hormones through activating the phospholipid- $\mathrm{CA}^{2+}$ pathway and stimulating the TPO activity (46-48). The expression of TSHR are high in PTC $(86.7 \%)$ and low in ATC $(23.8 \%)$. Whether the expression of TSHR in cells can be used to show the biological changes in cells due to thyroid malignant transformation, and to assess the invasion of its primary lesion combined with other clinical parameters need clarification.

In this study, it was confirmed that the cell membrane and cytoplasm were stained after immunohistochemistry. The expression on cell membrane was theoretically more accurate, but the expression in the cytoplasm may be affected by the incorrect TSHR protein positioning or the protein may enter the cytoplasm due to the lack of TSHR in the cytoplasm, aggravating staining and resulting in experimental errors, so the expression on cell membrane was used as an experimental standard. The 30 cases of thyroid benign tumors and 30 cases of para-carcinoma normal tissues selected showed the normal staining expression; the semi-quantitative calculation was performed using the positive cell percentage and cell staining intensity; cases with the score of approximately 4 points could be set as the control group. At the same time, 92 out of 162 cases of PTMC had a score less than 4 points, indicating low expression (56.8\%), and the remaining 70 cases indicated high expression (43.2\%). The univariate analysis of expression results and clinical parameters showed that the results were consistent with the BRAF gene detection. The TSHR protein was also associated with the diameter, capsular infiltration and lymph node metastasis of primary lesion of PTMC, but not related to age, gender, TNM staging and number of primary lesions. After the introduction of invasion, it was found that the low-expression TSHR indicates high invasion of primary lesion. The Chi-square test for trend was used for comparison between groups with greater than 3 central metastatic lymph nodes and less than or equal to 3 central metastatic lymph nodes, and the results revealed that the higher the number of metastatic lymph nodes was, the higher the proportion of low expression would be, and the larger the probability of invasion would also be (trend $\chi^{2}=5.704, \mathrm{P}=0.017$ ). Therefore, it is concluded that the larger diameter of primary lesion of PTMC leads to capsular infiltration, more lymph node metastasis and low expression of TSHR protein, and the TSHR expression is negatively correlated with invasion.

Through this study, it was found that although the single factor detection can identify and diagnose benign and malignant tumors, but it cannot independently determine and then conclude the invasion of malignant tumors, so it is feasible to apply BRAF gene combined with TSHR in the diagnosis of high invasiveness of PTMC. The univariate analysis was performed for them with clinical parameters collected, and the associations with risk factors were obtained. The results showed that there were 135 cases of BRAF gene mutations, including 74 cases of low expression TSHR and 61 cases of high expression TSHR. There were 27 cases of wild-type BRAF gene, including 18 cases of low expression TSHR and 9 cases of high expression TSHR. The coincidence coefficient obtained via chi-square test was $\mathrm{K}=0.06, \mathrm{P}=0.256$, and the coincidence rate was $51.2 \%$. Although the $\mathrm{BRAF}^{\mathrm{V} 600 \mathrm{E}}$ mutation was not correlated with the expression of TSHR protein, the coincidence coefficient indicated that they had different diagnostic significance in PTMC in clinical application; $\mathrm{BRAF}^{\mathrm{V} 600 \mathrm{E}}$ mutation and TSHR protein can be combined and applied in the prediction of PTMC invasion and lymph node metastasis, which may be more meaningful for clinical guidance.

Many studies have suggested that $(49,50)$ BRAF gene mutation is the most closely related to lymph node metastasis, followed by thyroid capsular infiltration. Russo et al (51) reported that the BRAF gene mutant type in PTMC is associated with cervical lymph node metastasis and TNM staging (III/IV). Wang et al (52) enrolled more than 300 cases of PTMC (clinical TNM staging of I/II) in the study, and found that $\mathrm{BRAF}^{\mathrm{V} 600 \mathrm{E}}$ mutation is related to the capsular infiltration and multiple lesions. Combined with our experiments, most conclusions were consistent with the views of experts and scholars, and some small differences might be caused by the impact of experimental environment, experimental techniques, uneven sample size and other clinical parameters not included. But in general, predicting the invasiveness (small cancer lesion and great metastasis) of PTMC should be combined with various factors. It is believed that the poorly differentiated and mutant primary lesion of PTMC has larger possibility of invasion, and the lesion is more likely to break through the capsule, leading to lymph node metastasis. However, is it feasible to combine preoperative FNAB pathological results (53) and blood marker examination for better prediction? We consider it is possible. Under reasonable indications, the application of BRAF gene and TSHR protein in the cytological pathological examination and preoperative serum detection of PTMC may have more reasonable guiding significance than the postoperative paraffin-embedded specimens. There have been few studies on the combined application of BRAF gene and TSHR protein, so subsequent in-depth exploration is still needed to confirm the experimental results.

\section{Acknowledgements}

Not applicable.

\section{Funding}

This research did not receive any specific grant from funding agencies in the public, commercial, or not-for-profit sectors.

\section{Availability of data and materials}

The datasets used and/or analyzed during the present study are available from the corresponding author on reasonable request. 


\section{Authors' contributions}

$\mathrm{CZ}$ and JL contributed to the conception of the study. YW designed the study and performed the research. SX performed the data analyses and wrote the manuscript. YZ helped perform the analysis with constructive discussions. All authors read and approved the final manuscript.

\section{Ethics approval and consent to participate}

The study was approved by the Ethics Committee of Liaocheng People's Hospital (Liaocheng, China) and written informed consents were signed by the patients or the guardians.

\section{Patient consent for publication}

Not applicable.

\section{Competing interests}

The authors declare that they have no competing interests.

\section{References}

1. Siegel R, Naishadham D and Jemal A: Cancer statistics, 2013. CA Cancer J Clin 63: 11-30, 2013.

2. Cox AE and LeBeau SO: Diagnosis and treatment of differentiated thyroid carcinoma. Radiol Clin North Am 49: 453-462, 2011.

3. Jemal A, Siegel R, Ward E, Hao Y, Xu J and Thun MJ: Cancer statistics, 2009. CA Cancer J Clin 59: 225-249, 2009.

4. Cao Y, Xia J, Li Y, Wang L and Jiang Z: Study on the effect of salt plus iodine on the hospitalization of thyroid diseases in a hospital. Chin J Health Stat 29: 236-242, 2012 (In Chinese).

5. Zhao H, Jiang W, Guan F, Hou F and Cheng H: Application of ${ }^{131} \mathrm{I}$ in the study of residual thyroid tissue dose after differentiated thyroid cancer. J Jilin Univ (Med Ed) 35: 191-194, 2009 (In Chinese).

6. Sciuto R, Romano L, Rea S, Marandino F, Sperduti I and Maini CL: Natural history and clinical outcome of differentiated thyroid carcinoma: A retrospective analysis of 1503 patients treated at a single institution. Ann Oncol 20: 1728-1735, 2009.

7. Choi YM, Kim TY, Song DE, Hong SJ, Jang EK, Jeon MJ, Han JM, Kim WG, Shong YK and Kim WB: Papillary thyroid carcinoma arising from a thyroglossal duct cyst: A single institution experience. Endocr J 60: 665-670, 2013.

8. Vergamini LB, Frazier AL, Abrantes FL, Ribeiro KB and Rodriguez-Galindo C: Increase in the incidence of differentiated thyroid carcinoma in children, adolescents, and young adults: A population-based study. J Pediatr 164: 1481-1485, 2014

9. Londero SC, Krogdahl A, Bastholt L, Overgaard J, Pedersen HB, Frisch T, Bentzen J, Pedersen PU, Christiansen P and Godballe C: Papillary thyroid carcinoma in Denmark 1996-2008: An investigation of changes in incidence. Cancer Epidemiol 37: e1-e6, 2013.

10. Radespiel-Tröger M, Batzler WU, Holleczek B, Luttmann S, Pritzkuleit R, Stabenow R, Urbschat I, Zeissig SR and Meyer M; Im Namen der Gesellschaft der epidemiologischen Krebsregister in Deutschland e.V: Rising incidence of papillary thyroid carcinoma in Germany. Bundesgesundheitsblat Gesundheitsforschung Gesundheitsschutz 57: 84-92, 2014 (In German).

11. Joshi P, Nair S, Nair D and Chaturvedi P: Incidence of occult papillary carcinoma of thyroid in Indian population: Case series and review of literature. J Cancer Res Ther 10: 693-695, 2014.

12. Wu LS and Milan SA: Management of microcarcinomas (papillary and medullary) of the thyroid. Curr Opin Oncol 25 27-32, 2013.

13. Moosa $\mathrm{M}$ and Mazzaferri EL: Occult thyroid carcinoma. Cancer 10: 180-188, 1997

14. Pacini F: Thyroid microcarcinoma. Best Pract Res Clin Endocrinol Metab 26: 421-429, 2012.
15. Kim NH, Beak SK, Baik SH, Choi DS and Kim SG: A patient with micropapillary thyroid carcinoma and macronodular lung metastasis: Stable disease for eight years without treatment. Thyroid 19: 309-311, 2009.

16. Zhang Y, Cui Z, Sun S, Ren Y, Xu J, Yao Y, Chen Q, Zhang W, Li R, Guan Z, et al: Study on the significance and method of cervical lymph node dissection in differentiated thyroid carcinoma. Chin J Pract Surg 31: 414-416, 2011 (In Chinese).

17. Robinson MJ and Cobb MH: Mitogen-activated protein kinase pathways. Curr Opin Cell Biol 9: 180-186, 1997.

18. MacCorkle RA and Tan TH: Mitogen-activated protein kinases in cell-cycle control. Cell Biochem Biophys 43: 451-461, 2005.

19. Zhang BH and Guan KL: Activation of B-Raf kinase requires phosphorylation of the conserved residues Thr598 and Ser601. EMBO J 19: 5429-5439, 2000.

20. Tufano RP, Teixeira GV, Bishop J, Carson KA and Xing M: BRAF mutation in papillary thyroid cancer and its value in tailoring initial treatment: A systematic review and metaanalysis. Medicine (Baltimore) 91: 274-286, 2012.

21. Xing M, Alzahrani AS, Carson KA, Viola D, Elisei R, Bendlova B, Yip L, Mian C, Vianello F, Tuttle RM, et al: Association between BRAF V600E mutation and mortality in patients with papillary thyroid cancer. JAMA 309: 1493-1501, 2013.

22. Chen W, Yin D, Lu X and Qiu X: Expression and significance of TSHR, ER and CyclinD1 in differentiated thyroid carcinoma. J Zhengzhou Univ (Med Sci) 5: 354, 2005 (In Chinese).

23. Shi Y,Zou M and Farid NR: Expression of thyrotrophin receptor gene in thyroid carcinoma is associated with a good prognosis. Clin Endocrinol (Oxf) 39: 269-274, 1993.

24. Tanaka K, Inoue H, Miki H, Masuda E, Kitaichi M, Komaki K, Uyama $\mathrm{T}$ and Monden Y: Relationship between prognostic score and thyrotropin receptor (TSH-R) in papillary thyroid carcinoma: Immunohistochemical detection of TSH-R. Br J Cancer 76: 594-599, 1997.

25. Liu X and Gao M: The relationship between the anti-oxidative conduction pathway of thyroxine and the invasion force of thyroid papillary carcinoma. Chin J Otorhinolaryngol Head Neck Surg 44: 287-291, 2009 (In Chinese).

26. Shi C, Qin H, Ding C, Sun Y, Lyu Y and Shi T: Association between BRAF V600E mutation and central lymph node metastasis in patients with papillary thyroid carcinoma. Zhonghua Zhong Liu Za Zhi 37: 123-127, 2015 (In Chinese).

27. Shi X, Liu R, Basolo F, Giannini R, Shen X, Teng D, Guan H, Shan Z, Teng W, Musholt TJ, et al: Differential clinicopathological risk and prognosis of major papillary thyroid cancer variants. J Clin Endocrinol Metab 101: 264-274, 2016.

28. Stewart BW and Kleihues P (eds): World Cancer Report. IARC Press, Lyon, 2003.

29. Kim HJ, Kim NK, Choi JH, Kim SW, Jin SM, Suh S, Bae JC, Min YK, Chung JH and Kim SW: Radioactive iodine ablation does not prevent recurrences in patients with papillary thyroid microcarcinoma. Clin Endocrinol (Oxf) 78: 614-620, 2013.

30. Lee KJ, Cho YJ, Kim JG and Lee DH: How many contralateral papillary thyroid carcinomas can be missed? World J Surg 37: 780-785, 2013.

31. Davies L and Welch HG: Current thyroid cancer trends in the United States. JAMA Otolaryngol Head Neck Surg 140: 317-322, 2014.

32. Pedrazzini L, Baroli A, Marzoli L, Guglielmi R and Papini E: Cancer recurrence in papillary thyroid microcarcinoma: a multivariate analysis on 231 patients with a 12-year follow-up. Minerva Endocrinol 38: 269-279, 2013.

33. Liu T and Qi J: Diagnosis and surgical treatment of differentiated thyroid carcinoma. Int J Endocrinol 26: 344-346, 2006.

34. Chung YJ, Lee JS, Park SY, Park HJ, Cho BY, Park SJ, Lee SY, Kang KH and Ryu HS: Histomorphological factors in the risk prediction of lymph node metastasis in papillary thyroid carcinoma. Histopathology 62: 578-588, 2013.

35. Bruno R, Giannasio P, Chiarella R, Capula C, Russo D, Filetti S and Costante G: Identification of a neck lump as a lymph node metastasis from an occult contralateral papillary microcarcinoma of the thyroid: Key role of thyroglobulin assay in the fine-needle aspirate. Thyroid 19: 531-533, 2009.

36. Dohán O, De la Vieja A, Paroder V, Riedel C, Artani M, Reed M, Ginter CS and Carrasco N: The sodium/iodide symporter: Characterization, regulation, and medical significance. Endorcrine Rev 24: 48-77, 2003.

37. Ikawa S, Fukui M, Ueyama Y, Tamaoki N, Yamamoto T and Toyoshima K: B-raf, a new member of the raf family, is activated by DNA rearrangement. Mol Cell Biol 8: 2651-2654, 1988. 
38. Ji Y and Xie N: Clinical study of BRAF gene mutation in thyroid papillary carcinoma. Guangdong Med J 30: 1183-1185, 2009 (In Chinese)

39. Kumar R, Angelini S, Czene K, Sauroja I, Hahka-Kemppinen M, Pyrhönen S and Hemminki K: BRAF mutations in metastatic melanoma: A possible association with clinical outcome. Clin Cancer Res 9: 3362-3368, 2003.

40. Bansal M, Gandhi M, Ferris RL, Nikiforova MN, Yip L, Carty SE and Nikiforov YE: Molecular and histopathologic characteristics of multifocal papillary thyroid carcinoma. Am J Surg Pathol 37: 1586-1591, 2013.

41. Jung CK, Little MP, Lubin JH, Brenner AV, Wells SA Jr, Sigurdson AJ and Nikiforov YE: The increase in thyroid cancer incidence during the last four decades is accompanied by a high frequency of BRAF mutations and a sharp increase in RAS mutations. J Clin Endocrinol Metab 99: E276-E285, 2014.

42. Lin KL, Wang OC, Zhang XH, Dai XX, Hu XQ and Qu JM: The BRAF mutation is predictive of aggressive clinicopathological characteristics in papillary thyroid microcarcinoma. Ann Surg Oncol 17: 3294-3300, 2010.

43. Kim SJ, Lee KE, Myong JP, Park JH, Jeon YK, Min HS, Park SY, Jung KC, Koo H and Youn YK: BRAF V600E mutation is associated with tumor aggressiveness in papillary thyroid cancer. World J Surg 36: 310-317, 2012.

44. Kwak JY, Jeong JJ, Kang SW, Park S, Choi JR, Park SJ, Kim EK and Chung WY: Study of peripheral BRAF(V600E) mutation as a possible novel marker for papillary thyroid carcinomas. Head Neck 35: 1630-1633, 2013.

45. Guan H, Guan H, Lu J, Rong S, Guo X and Li X: Meta-analysis of thyroid hormone level and thyroid cancer in Chinese population. J Environ Health 30: 1115-1116, 2013 (In Chinese).

46. Lu X, Ge M, Ling Z, Hu S, Xu Z, Zheng C, Tan Z and Chen C: Correlation and clinical significance of abnormal methylation of hMLH, NIS and TSHR in thyroid papillary carcinoma. Tumor 33: 445-453, 2013 (In Chinese).
47. Tonacchera M, Viacava P, Fanelli G, Agretti P, De Marco G, De Servi M, Di Cosmo C, Chiovato L, Pinchera A and Vitti P: The sodium-iodide symporter protein is always present at a low expression and confined to the cell membrane in nonfunctioning nonadenomatous nodules of toxic nodular goitre. Clin Endocrinol (Oxf) 61: 40-45, 2004

48. Smith JA, Fan CY, Zou C, Bodenner D and Kokoska MS: Methylation status of genes in papillary thyroid carcinoma. Arch Otolaryngol Head Neck Surg 133: 1006-1011, 2007.

49. Li C, Lee KC, Schneider EB and Zeiger MA: BRAF V600E mutation and its association with clinicopathological features of papillary thyroid cancer: Meta-analysis A. J Clin Endocrinol Metab 97: 4559-4570, 2012

50. Wang J, Wu G, Ma X, Liu Y, Chen $\mathrm{H}$ and Huang W: BRAF gene mutation and clinical significance in thyroid tumor tissue. Chin J Exp Surg 28: 1102-1104, 2011 (In Chinese).

51. Russo M, Malandrino P, Nicolosi ML, Manusia M, Marturano I, Trovato MA, Pellegriti G, Frasca F and Vigneri R: The BRAF(V600E) mutation influences the short- and mediumterm outcomes of classic papillary thyroid cancer, but is not an independent predictor of unfavorable outcome. Thyroid 24: 1267-1274, 2014.

52. Wang W, Lu R, Dong Y and Liang J: V600E BRAF gene mutation and I-II papillary thyroid cancer clinical pathological characteristics and prognosis of correlation analysis. Linchuang Zhongliuxue Zazhi 18: 1100-1103, 2013 (In Chinese).

53. Min JJ, Chung JK, Lee Y, Jeong J, Lee D, Jang J, Lee M and Cho B: Relationship between expression of the sodium/iodide symporter and (131)I uptake in recurrent lesions of differentiated thyroid carcinoma. Eur J Nucl Med 28: 639-645, 2001.

(c) (i) () This work is licensed under a Creative Commons

(c) AY NO ND Attribution-NonCommercial-NoDerivatives 4.0 International (CC BY-NC-ND 4.0) License. 